\title{
Hydration of Poly(phenylacetylene)s via Hydroboration
}

\author{
Toshio MASUdA, Toshiyuki OHTORI, and Toshinobu HIgASHIMURA \\ Department of Polymer Chemistry, Kyoto University, \\ Kyoto 606, Japan.
}

(Received June 19, 1979)

\begin{abstract}
S: The hydration of double bonds along the main chain in poly(phenylacetylene) [poly(PA)] was undertaken via hydroboration. Soluble and high-moleular-weight poly(PA)s obtained with $\mathrm{WCl}_{6}$ and $\mathrm{MoCl}_{5}$ as catalysts were used as starting polymers. Hydroboration was usually performed in tetrahydrofuran at $50^{\circ} \mathrm{C}$. The degree of hydration reached about $70 \%$. Poly $(\beta$ naphthylacetylene) also underwent hydroboration in a similar manner, whereas no reaction took place for poly(1-phenylpropyne) because of steric hindrance. The product from poly(PA) was a white powder soluble in polar solvents such as ethyl acetate, acetone, and phenylethanols which are all nonsolvents of poly(PA). The product was characterized by UV, IR, and ${ }^{13} \mathrm{C} N M R$ spectroscopies.

KEY WORDS Polymer Reaction / Poly(phenylacetylene) / Poly $(\beta$ naphthylacetylene) / Poly(1-phenylpropyne) / Hydration / Hydroboration /

Polymer Alcohol /
\end{abstract}

The present paper deals with the hydration of poly(phenylacetylene) [poly(PA)] via hydroboration for the purpose of clarifying the followings: (i) the reactivity of conjugated double bonds along the main chain in poly(PA), (ii) the influence of substituents on the hydroboration of the main chain, and (iii) the possibility of synthesizing a novel polymer which possesses hydrophobic and hydrophilic groups.

Though carotenes are not high polymers, they are polyenes possessing ten or eleven conjugated double bonds. Structural analysis of carotenes was performed as early as about 1930 by catalytic hydrogenation and oxidative decomposition, ${ }^{1}$ giving evidence that the conjugated double bonds of polyenes can undergo chemical reactions.

There have been, however, few studies on reactions of the conjugated double bonds in acetylenic polymers. Some polyacetylene complexes have been reported to be highly conducting. ${ }^{2.3}$ They are prepared by reactions of the film of insoluble polyacetylene with electron-attracting species such as halogens and with electron-donating species like sodium. It has been found that in the halogenation of poly(PA), bromine adds to every fourth double bond in the main chain, and chlorine to every third double bond. $^{4}$
The $\mathrm{WCl}_{6}$ - and $\mathrm{MoCl}_{5}$-catalyzed polymerizations of phenylacetylene selectively give soluble poly(PA)s which possess high molecular weights $(6,000-$ $15,000) .{ }^{5}$ It seems of interest to perform solution reactions of the poly(PA)s in order to examine the ${ }^{\circ}$ reactivity of the double bond along the main chain. In the present sutudy, hydroboration was chosen as a solution reaction. If the reaction proceeds completely and a hydroxyl group is selectively introduced on the carbon which has no phenyl group, then the reaction scheme is expressed as follows.

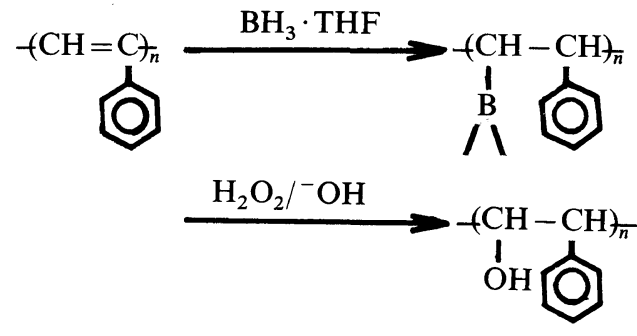

EXPERIMENTAL

$\operatorname{Poly}(\mathrm{PA}),{ }^{5} \quad \operatorname{poly}(\beta$-naphthylacetylene $) \quad[$ poly$(\beta \mathrm{NA})]^{6}$ and poly(1-phenylpropyne) $[\text { poly(PP) }]^{7}$ were prepared as described before.

A typical procedure of hydroboration is as fol- 
lows: A solution of borane in tetrahydrofuran (Aldrich Chem.; concn $\left.0.75 \mathrm{~mol} \mathrm{dm}^{-3}\right)\left(12 \mathrm{~cm}^{3}, 9.0\right.$ mmol) was added to poly(PA) $(306 \mathrm{mg}, 3.0 \mathrm{mmol}$ based on repeat unit) under dry nitrogen. The mixture was maintained at $50^{\circ} \mathrm{C}$ for $48 \mathrm{~h}$. To the reaction mixture were added tetrahydrofuran (THF) $\left(40 \mathrm{~cm}^{3}\right), 6 \mathrm{~N}$ aqueous sodium hydroxide solution $\left(5.0 \mathrm{~cm}^{3}, 30 \mathrm{mmol}\right)$ and $30 \%$ hydrogen peroxide $\left(5.0 \mathrm{~cm}^{3}, 44 \mathrm{mmol}\right)$ in this order. The solution was stirred at room temperature for $24 \mathrm{~h}$. The remaining peroxide was decomposed by the addition of $20 \%$ aqueous sodium bisulfite solution. The solution was neutralized by $1 N$ hydrochloric acid, and then THF and water were evaporated under a reduced pressure. To the residue (product and salts) was added THF $\left(10 \mathrm{~cm}^{3}\right)$; salts were filtered off, and the solution was poured into a mixture $\left(200 \mathrm{~cm}^{3}\right)$ of methanol and water $(1: 1 \mathrm{vol}$ ratio). The product precipitated was isolated and purified by reprecipitation.

Conversion (degree of hydration) was determined by the elemental analysis or IR spectrum of product. UV-visible and IR spectra were recorded on Shimadzu UV190 and IR27G spectrophotometers, respectively. ${ }^{13} \mathrm{C}$ NMR spectra were observed in $\mathrm{CDCl}_{3}$ solution $(20 \mathrm{w} / \mathrm{v} \%)$ by using a JNM FX100 spectrometer.

\section{RESULTS AND DISCUSSION}

\section{Reactivity and Asymptotic Conversion}

As seen from Figure 1, the hydroboration rate of poly(PA) prepared with $\mathrm{WCl}_{6}$ [poly(PA)-W] increased with increasing temperature in the range of $0-50^{\circ} \mathrm{C}$. A three-fold excess of borane against substrate was usually used to make the reaction proceed fast. The reaction was, however, too sluggish at $0^{\circ} \mathrm{C}$. At $50^{\circ} \mathrm{C}$, the convesion (degree of hydration) reached $c a .60 \%$ within $24 \mathrm{~h}$, and leveled off even though the reaction was continued for seven days. This limit in conversion is thought to be due to a steric effect against farther hydroboration. Also the increase in the ratio of borane to substrate hardly enhanced the asymptotic conversion (Table I, No. 2).

In an attempt to obtain a product having a higher degree of hydration, a hydration product was again treated with borane under the same reaction conditions (Table I, No 3). The conversion after the repeated hydroboration was $69 \%$, which shows only a small increase relative to the conversion of starting polymer $(61 \%)$.

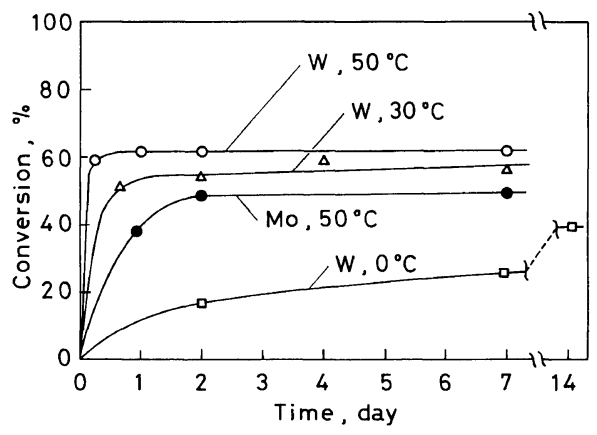

Figure 1. Time-conversion curves for the hydration of poly(PA) via hydroboration: $\left[\mathrm{BH}_{3}\right]_{0} /[\mathrm{C}=\mathrm{C}]_{0}=3.0$, $[\mathrm{C}=\mathrm{C}]_{0}=0.25 \mathrm{~mol} \mathrm{dm}^{-3}$, in THF. (In the Figure "W, $50^{\circ} \mathrm{C}$ " stands for the hydroboration of poly(PA)-W at $50^{\circ} \mathrm{C}$, and so on.)

$\operatorname{Poly}(\mathrm{PA})$ obtained with $\mathrm{MoCl}_{5}$ [poly(PA)-Mo] is rich in $c$ is structure, compared with poly(PA)-W. ${ }^{8}$ The reaction rate of poly(PA)-Mo was fairly slower than that of poly(PA)-W, and the asymptotic conversion for poly(PA)-Mo was only $c a$. $50 \%$. (see Figure 1 and Table I, No 4). This means that the geometric structure of polymer affects both the reaction rate and asymptotic conversion.

Hydroboration of homologs of poly(PA) was undertaken (Table I, No 5 and 6). Poly $(\beta$ NA) and poly(PP) which were used as starting polymers were obtained with $\mathrm{WCl}_{6}$-based catalysts. ${ }^{6.7}$ The conversion for poly $(\beta \mathrm{NA})$ was $c a .66 \%$ after reaction at $50^{\circ} \mathrm{C}$ for $48 \mathrm{~h}$; it is very close to the conversion of poly(PA). On the other hand, poly(PP) did not react at all under the same conditions (there were no changes in elemental analysis, IR spectrum, and solubility before and after the reaction). The repeat units of poly(PA) and poly $(\beta \mathrm{NA})$ are regarded as trisubstituted olefins, while that of poly(PP) as a tetrasubstituted olefin. Thus, the inertness of poly(PP) is in agreement with the fact that some of the hindered tetra-substituted olefins fail to undergo hydroboration. ${ }^{9,10}$

In the hydroboration of polybutadiene and polyisoprene, the reaction mixture becomes a gel because two or three hydrogens in a borane molecule take part in the reaction. ${ }^{11}$ In contrast to this, no gel was formed in the hydroboration of poly(PA); this indicates that only one hydrogen of the borane molecule participates in the reaction due to steric hindrance. 
Hydroboration of Poly(phenylacetylene)s

Table I. Hydration of poly(PA) and its homologs via hydroboration ${ }^{\mathrm{a}}$

\begin{tabular}{|c|c|c|c|c|c|}
\hline No. & $\begin{array}{l}\text { Starting } \\
\text { polymer }\end{array}$ & $\frac{\text { Conversion }^{\mathbf{b}}}{\%}$ & $M_{n}$ & Color & $\begin{array}{l}\text { Softening } \\
\text { point } /{ }^{\circ} \mathrm{C}\end{array}$ \\
\hline 1 & Poly(PA)-W & 61.4 & $\begin{array}{c}2700 \\
(9300)^{c}\end{array}$ & $\begin{array}{c}\text { White } \\
\text { (Dark brown) }^{\mathrm{c}}\end{array}$ & $\begin{array}{c}210-217 \\
(221-222)^{\mathrm{c}}\end{array}$ \\
\hline $2^{d}$ & Poly(PA)-W & 65.2 & $\begin{array}{c}4200 \\
(9300)\end{array}$ & $\begin{array}{c}\text { White } \\
\text { (Dark brown) }\end{array}$ & $\begin{array}{c}213-221 \\
(221-222)\end{array}$ \\
\hline 3 & $\operatorname{Poly}(\mathrm{PA})-\mathrm{W}-\mathrm{OH}^{\mathrm{e}}$ & $\begin{array}{c}69.3 \\
(61.4)\end{array}$ & $\begin{array}{c}2700 \\
(2700)\end{array}$ & $\begin{array}{l}\text { White } \\
\text { (White) }\end{array}$ & $\begin{array}{c}179-209 \\
(210-217)\end{array}$ \\
\hline 4 & Poly(PA)-Mo & 48.5 & $\begin{array}{c}2100 \\
(6300)\end{array}$ & $\begin{array}{l}\text { White } \\
\text { (Yellow) }\end{array}$ & $\begin{array}{c}198-207 \\
(214-215)\end{array}$ \\
\hline 5 & $\operatorname{Poly}(\beta$ NA $)$ & 66.3 & $\begin{array}{c}2300 \\
(9000)\end{array}$ & $\begin{array}{l}\text { Light yellow } \\
\text { (Dark brown) }\end{array}$ & $\begin{array}{c}205-238 \\
(235-244)\end{array}$ \\
\hline 6 & Poly(PP) & $\sim 0$ & $\begin{array}{c}1900 \\
(5200)\end{array}$ & $\begin{array}{l}\text { White } \\
\text { (White) }\end{array}$ & $\begin{array}{c}221-240 \\
(230-240)\end{array}$ \\
\hline
\end{tabular}

${ }^{\mathrm{a}}[\mathrm{C}=\mathrm{C}]_{0}=0.25 \mathrm{~mol} \mathrm{dm}^{-3} ;\left[\mathrm{BH}_{3}\right]_{0}=0.75 \mathrm{~mol} \mathrm{dm}^{-3} ; 50^{\circ} \mathrm{C} ; 48 \mathrm{~h}$.

b Determined by elemental analysis.

c The values and color in parentheses are those of the starting polymer.

d $[\mathrm{C}=\mathrm{C}]_{0}=0.125 \mathrm{~mol} \mathrm{dm}^{-3}$.

e The reaction product of No 1 .

\section{Properties of the Hydration Products}

Molecular Weight. The molecular weights of hydration products generally decreased to about one third of those of the starting polymers (Table I). For example, the molecular weight of poly(PA) was 9300 (DP 91), whereas that of the reaction product was 2700 (DP ca. 24, taking the conversion into account). The decrease in molecular weight occurred at both stages of hydroboration and oxidative decomposition.

Color. The product from poly(PA) was a white powder. The product from $\operatorname{poly}(\beta \mathrm{NA})$ was light yellow, though the degree of hydration was similar to that of poly(PA); this seems due to the more conjugated substituent. In general, a large difference in the colors of starting polymer and product made it possible to estimate the conversion during reaction. In the UV-visible spectrum of hydrated poly(PA), no

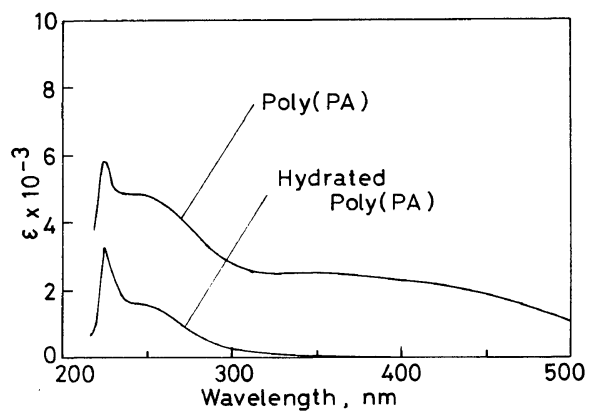

Figure 2. UV-visible spectra of poly(PA) and hydrated poly(PA) (the sample from the reaction of Table I, No 1).

Table II. Solubility of hydrated polymers

\begin{tabular}{|c|c|c|}
\hline Solvent & $\operatorname{Poly}(\mathrm{PA})$ and $\operatorname{poly}(\beta \mathrm{NA})$ & $\begin{array}{c}\text { Products from } \\
\text { poly(PA) and poly }(\beta \mathrm{NA})\end{array}$ \\
\hline $\mathrm{CCl}_{4}$ & 0 & $x$ \\
\hline $\mathrm{C}_{6} \mathrm{H}_{6}$ & 0 & 0 \\
\hline$\left(\mathrm{CH}_{2} \mathrm{Cl}\right)_{2}$ & 0 & 0 \\
\hline $\mathrm{CH}_{3} \mathrm{CO}_{2} \mathrm{C}_{2} \mathrm{H}_{5}$ & $x$ & 0 \\
\hline$\left(\mathrm{CH}_{3}\right)_{2} \mathrm{C}=\mathrm{O}$ & $x$ & 0 \\
\hline $\mathrm{CH}_{3} \mathrm{CH}(\mathrm{Ph}) \mathrm{OH}$ & $x$ & 0 \\
\hline $\mathrm{PhCH}_{2} \mathrm{CH}_{2} \mathrm{OH}$ & $x$ & 0 \\
\hline $\mathrm{CH}_{3} \mathrm{OH}$ & $x$ & $x$ \\
\hline
\end{tabular}


absorption was observed in the range where the wavelength was greater than $400 \mathrm{~nm}$ (Figure 2).

Solubility. The solubilities of poly(PA), $\operatorname{poly}(\beta \mathrm{NA})$, and products from these polymers are listed in Table II. The hydration products were insoluble in carbon tetrachloride as a consequence of the introduction of hydroxyl groups. Also, the products were soluble in polar solvents such as ethyl acetate and acetone which are nonsolvents of the starting polymers. It is noteworthy that the products also dissolve in 1- and 2-phenylethanols which have structures similar to the repeat unit of hydrated poly(PA).

Softening Point. While poly(PA)s prepared with $\mathrm{WCl}_{6}$ and $\mathrm{MoCl}_{5}$ as polymerization catalysts possess softening points in a region of $215-225^{\circ} \mathrm{C}$, their hydration products showed lower and broader softening temperature (Table I). This seems to be due to both the decrease in molecular weight which occurs during the reaction and the imperfect hydration. A similar tendency is seen also in the softening points of $\operatorname{poly}(\beta \mathrm{NA})$ and its hydration product.

\section{Structure of the Hydration Products}

$I R$ Spectra. In the IR spectrum of the product from poly(PA), absorptions appeared at $3400 \mathrm{~cm}^{-1}$ (O-H stretching), $2900 \mathrm{~cm}^{-1}$ (paraffinic $\mathrm{C}-\mathrm{H}$ stretching), and $1070 \mathrm{~cm}^{-1}$ (C-O stretching), besides the bands seen in poly(PA) (Figure 3). On the other hand the absorption at $870 \mathrm{~cm}^{-1}$, which is observed in poly(PA), disappeared; it has been known that the absorption is due to the double bonds in the main chain of poly(PA) and becomes larger as the cis content increases. ${ }^{8}$ In this way, the spectrum of the hydration product indicates that the expected reaction has taken place. It is noticed that the spectrum of the product resembles the two phenylethanols, especially 2-phenylethanol. No difference was observed between the IR spectra of products from poly(PA)-W and poly(PA)-Mo.

Figure 4 shows the relationship between the conversion in hydration determined by elemental analysis and the ratio of absorbances at 2900 and $1490 \mathrm{~cm}^{-1}\left(D_{2900} / D_{1490}\right)$ in the IR spectrum of product. It is quite obvious that the ratio of absorbances is proportional to the conversion. This means that the paraffinic hydrogen increases in proportion to the conversion. Therefore, the degree of hydration can be determined from the IR spectrum of product by use of Figure 4 . Not only $D_{2900} / D_{1490}$ but also

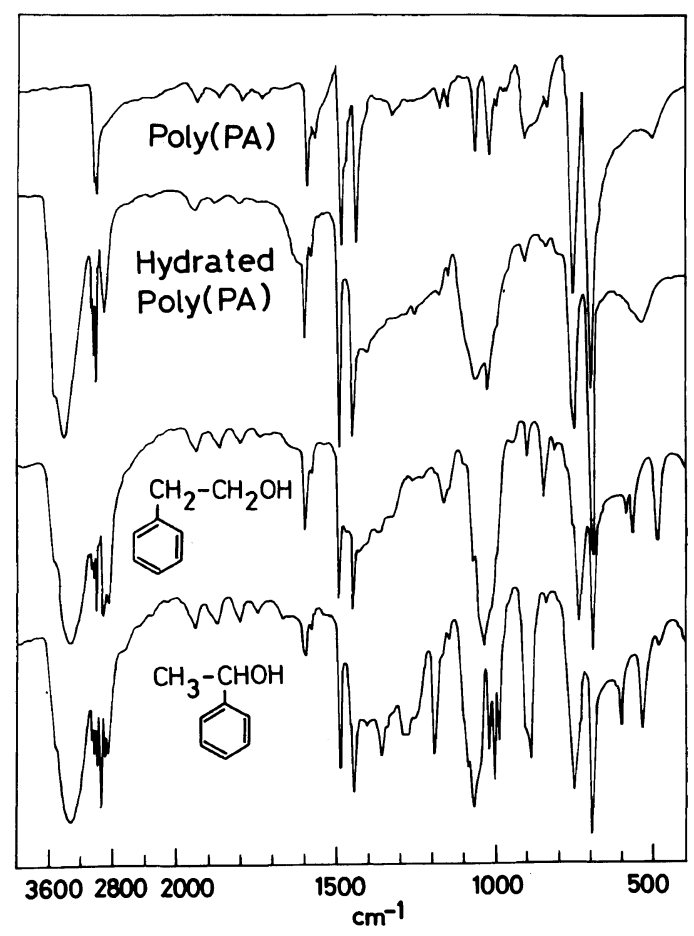

Figure 3. IR spectra of poly(PA), hydrated poly(PA), and phenylethanols.

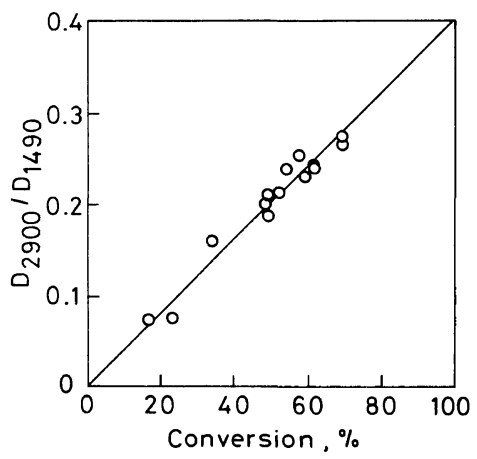

Figure 4. Relationship between the conversion in hydration and the ratio of $D_{2900} / D_{1490}$ in the IR spectrum of product.

$D_{2900} / D_{750}$ and $D_{2900} / D_{690}$ were proportional to the conversion.

${ }^{13}$ C NMR Spectra. Figure 5 shows the ${ }^{13}$ C NMR spectra of poly(PA) and its hydration product. In the spectrum of poly(PA), peaks appear only in the region for the $\mathrm{sp}^{2}$ carbons (120-150 ppm vs. TMS). Besides these peaks, two broad peaks were observed at $35-60 \mathrm{ppm}$ and $65-85 \mathrm{ppm}$ in the spectrum of 


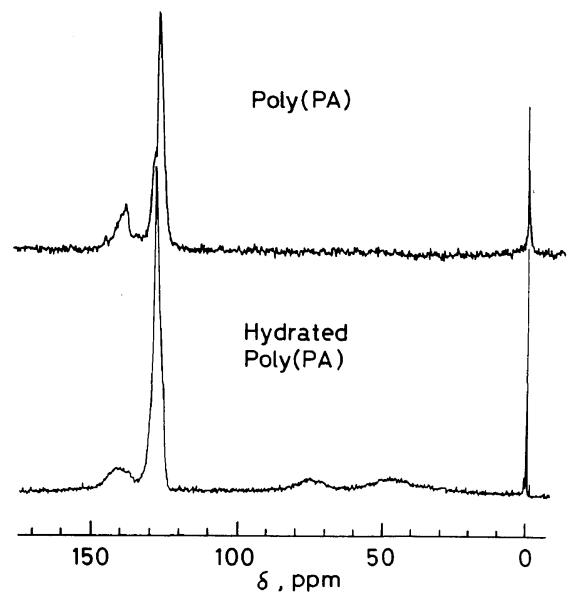

${ }^{13} \mathrm{C}$ NMR spectra

Figure 5. ${ }^{13} \mathrm{C}$ NMR spectra of poly(PA) and hydrated poly(PA).

hydration product. These peaks seem to be due to $\mathrm{sp}^{3}$ carbons formed by the addition of $\mathrm{H}$ and $\mathrm{OH}$ to the double bond of the main chain. The reason why these peaks are broad may be that the unreacted double bonds which distribute randomly in the main chain do not provide a regular structure to the hydration product.

Phenylethanols (1- and 2-) are regarded as lowmolecular-weight model compounds for the hydration product. The ${ }^{13} \mathrm{C}$ NMR chemical shifts of the $\mathrm{sp}^{3}$ carbons in 1- and 2- phenylethanols observed are as follows.

$$
\begin{array}{ll}
\mathrm{CH}_{3} \mathrm{CH}(\mathrm{Ph}) \mathrm{OH}: \quad \begin{aligned}
69.82(\mathrm{CH}, \mathrm{d}), 25.15 \mathrm{ppm} \\
\left(\mathrm{CH}_{3}, \mathrm{q}\right) .
\end{aligned} \\
& \\
\mathrm{PhCH}_{2} \mathrm{CH}_{2} \mathrm{OH}: & 63.28(\mathrm{COH}, \mathrm{t}), 39.16 \mathrm{ppm}
\end{array}
$$$$
(\mathrm{PhC}, \mathrm{t}) \text {. }
$$

The difference between the chemical shifts of two $\mathrm{sp}^{3}$ carbons in 1-phenylethanol is $44.7 \mathrm{ppm}$, and that in 2-phenylethanol is $24.1 \mathrm{ppm}$. The difference between the centers of chemical shifts of $\mathrm{sp}^{3}$ carbons in the product is about $27 \mathrm{ppm}$. Hence, it is concluded that the hydroxyl group has mainly been introduced on the carbon which has no phenyl group. This agrees with the finding that the IR spectrum of hydration product resembles that of 2-phenylethanol rather than that of 1-phenylethanol.

The product from poly(PA) in the present study can be regarded as a copolymer of $\beta$-hydroxystyrene and phenylacetylene. The product is, in other words, a polymer containing three functional groups, that is, phenyl and hydroxyl groups and a carbon-carbon double bond.

In conclusion, poly(PA) exhibited a sufficient reactivity in the hydroboration of the double bond in the main chain to give a product with the degree of hydration of $c a .60 \%$. Poly $(\beta \mathrm{NA})$ reacted in a similar manner but poly(PP) did not. The hydration products were more soluble in polar solvents as a consequence of the introduction of hydroxyl groups.

\section{REFERENCES}

1. R. Ramage, "Chemistry of Terpenes and Terpenoids," Academic Press, London, 1972, Chapter 6.

2. H. Shirakawa, E. D. Louis, A. G. MacDiarmid, C. K. Chiang, and A. J. Heeger, J. Chem. Soc., Chem. Commun., 578 (1977).

3. C. K. Chiang, M. A. Druy, S. C. Gau, A. J. Heeger, E. J. Louis, A. G. MacDiarmid, Y. W. Park, and H. Shirakawa, J. Am. Chem. Soc., 100, 1014 (1978).

4. P. S. Woon and M. F. Farona, J. Polym. Sci., Polym. Lett. Ed., 13, 567 (1975).

5. T. Masuda, K. Hasegawa, and 'T. Higashimura, Macromolecules, 7, 728 (1974), and subsequent papers.

6. T. Ohtori, T. Masuda, and T. Higashimura, Polym. J., 11, 805 (1979).

7. N. Sasaki, T. Masuda, and T. Higashimura, Macromolecules, 9, 664 (1976).

8. T. Masuda, N. Sasaki, and T. Higashimura, Macromolecules, 8, 717 (1975).

9. G. Zweifel and H. C. Brown, "Organic Reactions," Vol. XIII, A. C. Cope, Editor-in-Chief, John Wiley \& Sons, Inc., New York, N.Y., 1963, p 1.

10. H. C. Brown, "Organic Syntheses via Boranes," John Wiley \& Sons, Inc., New York, N.Y., 1975, p 3.

11. Y. Minoura and H. Ikeda, J. Appl. Polym. Sci., 15, 2219 (1971). 